\title{
Recent Economic Developments in Perspective
}

\author{
KEITH M. CARLSON
}

\section{A}

SUPERFICIAL reading of economic data sug. gests that the first half of 1974 was apparently one of the worst periods of economic attainment in the postWorld War II period, with indexes of real growth and the price level moving adversely at the same time. The reported decline in real product for the two quarters was exceeded only during the recessions of 1953-54 and 1957-58. At the same time the reported inflation rate was the highest for all successive twoquarter periods since 1947.

The purpose of this article is to review economic developments in the first half of 1974 , with special emphasis on the interpretation of the GNP data. These data will be examined and compared with other time series to determine if any inconsistent signals are being emitted as to the course of the economy. ${ }^{1}$ To place the recent experience in perspective, the course of the latest economic expansion-from late 1970 to present - will be compared with other expansion periods in the United States over the last twenty years. The two most recent quarters are included in this comparison to give the current position of the U.S. economy some perspective, without at-

\footnotetext{
¿For an exercise with similar objectives, see Geoffrey Moore, "Recession?", Economic Outlook USA, a quarterly publication of the Survey Research Center at the University of Miehigan (Summer 1974), pp. $=5$.
}

tempting to determine if the most recent experience will be classified as a recession.

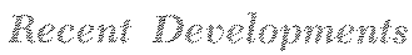

Total spending rebounded somewhat in the second quarter after slowing sharply in the first quarter. Consumer spending increased, with purchases of durable goods rising sharply from the depressed rate of spending last winter. Business investment also advanced rapidly in the second quarter.

Real product in the second quarter was below the first quarter, and since fourth quarter 1973 this measure of real activity has declined at a 4 percent annual rate. By comparison, real product had increased at a 2.I percent annual rate in the previous three quarters and at a 6.7 percent average annual rate from fourth quarter 1970 - the trough of the previous recession to first quarter 1973.

Industrial production, on the other hand, is up somewhat from the depressed levels of last winter. Though advances have been sluggish and irregular since February, industrial production was up at a 1.9 percent annual rate from February to July. Although this gain is not particularly impressive, it should be noted that industrial production growth has been dampened by work stoppages in various industries. For the first seven months of $1974,29.5$ million man- 
days were lost because of work stoppages, compared to 13.1 million mandays lost in the comparable period of 1973.

Despite irregular movements in industrial production thus far in 1974, employment conditions have been remarkably strong. Total employment, after holding steady from October 1973 to April 1974, has since increased at a 2.5 percent annual rate. Unemployment has changed little since January, averaging 5.2 percent of the labor force.

Prices have continued to increase very rapidly. The general price level has risen at a 9 percent annual rate since early 1973 , compared to about a 4 percent increase in the previous year. Consumer prices have advanced at a 10 percent average rate since early 1973 , and prices for wholesale industrial commodities have increased at a 20 percent average rate.

\section{Interpretation of GNP Dom}

A controversial aspect of the recent data is whether or not the first half figures indicate recession. It is well known that a shorthand method of determining whether or not a recession has occurred is to examine the movements of real product - in particular whether or not real product declines for two consecutive quarters. But the National Bureau of Economic Research (NBER) emphasizes that the label of recession is not determined in such a simple manner." Rather, the NBER makes such a determination from a much broader data base and uses the criteria of duration, severity, and the degree of diffusion.

The question of whether or not a particular period of economic experience should be defined as a recession is of little consequence for economic policy. Such labeling is helpful in later years since identification of recession periods assists in the interpretation of past economic events. What is important for the policymaker is whether or not a slowdown is occurring, and if so, is some kind of countercyclical action necessary in light of the objectives of policymakers.

To assess the meaning and significance of the most recent GNP data, other relevent time series are

\footnotetext{
"See Geoffrey Moore, "Recession?", and as a general reference, Victor Zarnowitz, ed., The Business Cycle Today, Fiftieth Anniversary Colloquium I (New York: National Bureau of Economic Research, 1972).
}

PRODUCTION AND EMPLO MENT

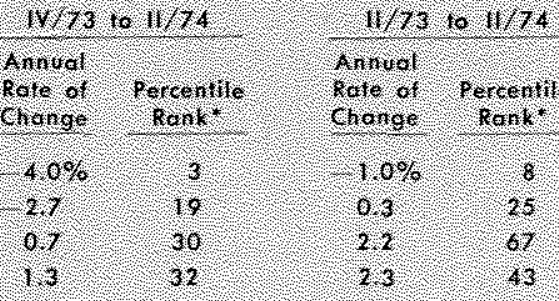

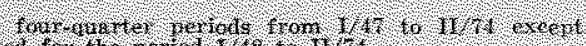

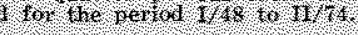

ranked according to rates of change for the period from 1947 or 1948 to the present. In this way, what appear to be extremes for prices and real GNP can be checked against other series measuring prices and real economic activity to determine to what extent the GNP data are providing consistent signals. Industrial production and employment are considered as complementary indicators of real activity. For prices, alternatives to the GNP deflator are consumer prices and wholesale prices. Each of the alternative measures is designed for its own purpose, and none is meant to substitute for the GNP measures. Yet, in past periods of several months duration, alternative time series relating to, say, real activity have tended to move in concert with one another.

Tables I and II provide percentile rankings for various measures of real economic activity and prices. A percentile ranking is a shorthand method of summarizing the movement of a particular time series in a specified time period relative to the historical movement of that series. A ranking of a specified rate of change in the 50th percentile, for example, indicates there were as many observations above as below that rate of change. High percentile rankings (greater than 50 but not more than 100 ) indicate rates of change that are high relative to past experience. Low percentile rankings (less than 50 but not less than zero) indicate rates of change that are low relative to past experience.

Table I shows percentile rankings for alternative measures of real economic activity. It should be noted that real GNP is the only series in this table which is computed by deflating nominal magnitudes. The other series involve more direct measures of physical production and employment. The 4 percent annual rate of decline for real GNP from fourth quarter last year to second quarter 1974 ranked in the 3 rd percentile. In other words, the last two quarter's decline in real GNP ranked very poorly relative to economic experi- 


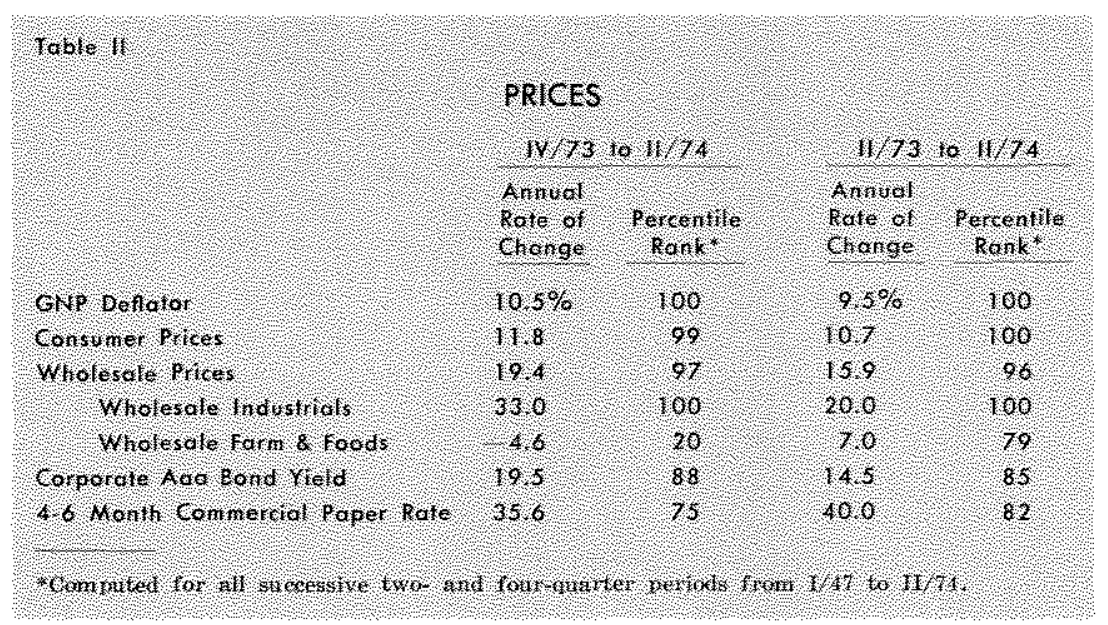

credit are ranked in Table II. The GNP deflator was in the 100th percentile; that is, the rate of change of the GNP deflator over the last two quarters was the lighest for all successive two quarters since 1947. This extreme is confirmed by both consumer prices and wholesale prices, and to a lesser extent by short- and long-term interest rates.

In summary, there is reason to doubt whether the decline in real product was as severe as indicated by constant dollar GNP. Measures of industrial production and employment do not show a corresponding degree of severity. The price ence since 1947, exceeding only 3 percent of all other successive two-quarter periods.

The question being asked here is whether or not the severity of the real GNP decline is borne out by other measures of real activity. Industrial production growth for the last two quarters was in the 19 th percentile. Total employment was in the 30 th percentile, while payroll employment growth was greater than 32 percent of all other two-quarter periods since 1947 . Examination of the record for the past four quarters shows a similar pattern.

Substantially higher percentile rankings for industrial production and employment than for real GNP indicate that real GNP may be providing misleading signals as to how severe the recent downturn really was. Though the source of the discrepancy cannot be readily identified, it should be pointed out that with severe inflation and/or substantial changes in relative prices, any figures denominated in dollars, or making use of calculations involving dollars, are suspect because of index number problems inherent in the measurement of price change. ${ }^{*}$

Though the chief question of interest is whether real activity declined as much as the GNP data indicate, there is a subsidiary question - is the rapid change in the GNP dellator confirmed by other price series? For purposes of comparison, consumer prices, wholesale prices, and the price of short- and long-term

\footnotetext{
"This point has also been made in Moore, "Recession?". For a recent discussion of price indexes, see Denis S. Kamosky, "A Priner on the Consumer Price Index," this Review (July $1974)$, pp. $2-7$.
} situation, on the other hand, appears without doubt to be one of the worst in the postwar period. Comparisons of this type do not yield definite conclusions. but it does appear that past patterns of consistency anong alternative measures of real product can be altered when relative prices change suddenly or substantially.

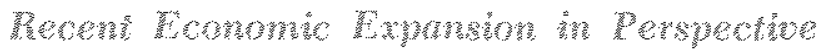

To provide additional perspective, the economic events of 1974 are examined in a business cycle context. The current expansion - from late 1970 to the

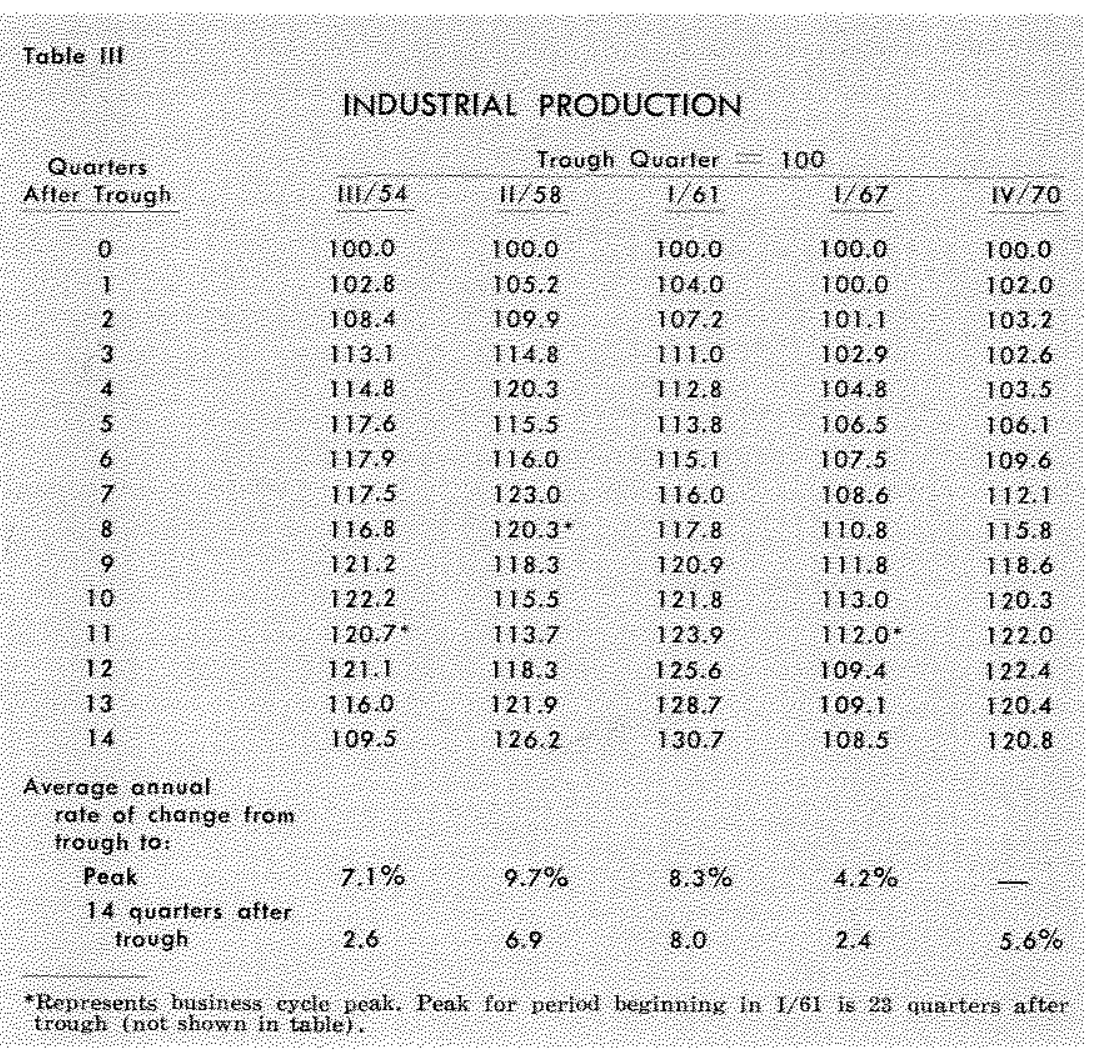


Table iv

\section{PAYROLL EMPLOYMENT}

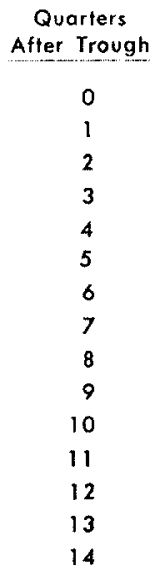

Average annual rale of change from trough to:

Peak

14 quarters after trough

\begin{tabular}{|c|c|c|c|}
\hline & \multicolumn{3}{|c|}{ Trough Quarter $=100$} \\
\hline $111 / 54$ & $11 / 58$ & $1 / 61$ & $1 / 67$ \\
\hline 100.0 & 100.0 & 100.0 & 100.0 \\
\hline 100.7 & 100.6 & 100.4 & 100.4 \\
\hline 101.7 & 101.8 & 101.3 & 101.0 \\
\hline 103.5 & 103.5 & 102.1 & 101.9 \\
\hline 104.6 & 105.1 & 102.8 & 102.6 \\
\hline 105.7 & 105.1 & 103.8 & 103.5 \\
\hline 106.8 & 105.4 & 104.3 & 104.4 \\
\hline 107.5 & 106.9 & 104.6 & 105.4 \\
\hline 107.2 & $107.1^{*}$ & 104.8 & 106.4 \\
\hline 108.3 & 106.6 & 105.7 & 107.3 \\
\hline 108.7 & 105.9 & 106.3 & 108.0 \\
\hline $108.8^{*}$ & 105.2 & 107.0 & 108.5 \\
\hline 108.6 & 105.7 & 107.6 & 108.7 \\
\hline 107.7 & 106.6 & 108.5 & 108.4 \\
\hline 105.8 & 107.4 & 109.5 & 108.0 \\
\hline
\end{tabular}

IV $/ 70$

100.0

100.3

100.6

100.8

101.4

102.4

103.4

104.1

105.3

106.5

107.5

108.0

109.2

109.4

109.9

four quarters. Though the decline from fourth quarter 1973 to second quarter 1974 places industrial production well below the comparable position in the long 1961-66 expansion, the current level of industrial production (second quarter 1974) is about average for comparable periods measured from trough reference points.

The table for payroll employment (Table IV) shows greater similarity during expansions than for industrial production. Though, initially, payroll employment in the most recent expansion lagged other expansions, it has since caught up. In fact, looking at all periods 14 quarters after the trough, the current expansion shows the best performance for payroll employment in the post-war period.

The position of the economy in 1974 is about average when viewed relative to progress in other postwar periods of economic expansion. The current

* Represents business cycle peak. Peak for period beginning in $1 / 61$ is 23 quarters afte trough (not shown in table).

present - is compared with other periods of expansion. Even though there is still some question as to whether or not the first half of 1974 will be classified as a recession, it is useful to compare the position of the economy relative to the recession trough with similar periods in the past. This most recent expansion of three and one-half years is compared with previous expansions from 1967 to 1969,1961 to 1966,1958 to 1960 , and 1954 to $1957 .{ }^{4}$

amination of the movement of industrial production (Table III, p. 4) in postwar economic expansions indicates that the most recent expansion has not been substantially different from other postwar cyclical expansions. Of course, each expansion is unique, and the most recent expansion is characterized by a slow start which picked up steam after about

4The NBER expansion of 1961-1969 has been divided into two subperiods of expansion from I/1961 to IV/1966 and from I/1967 to IV/1969. This division does not dispute the judgment of the NBER, but helps to provide additional perspective on the relationship between money and measures of economic activity. For general discussion of NBER procedures and methods, see Zarnowitz, The Business Cycle Today.

Toble V

\begin{tabular}{|c|c|c|c|c|c|}
\hline \multirow{2}{*}{$\begin{array}{l}\text { Quarlers } \\
\text { After Trough }\end{array}$} & \multicolumn{4}{|c|}{ Trough Quarter $=100$} & \multirow[b]{2}{*}{$1 V / 70$} \\
\hline & $111 / 54$ & $11 / 58$ & $1 / 61$ & $1 / 67$ & \\
\hline 0 & 100.0 & 100.0 & 100.0 & 100.0 & 100.0 \\
\hline 1 & 99.6 & 100.0 & 100.0 & 100.6 & 100.9 \\
\hline 2 & 99.8 & 100.0 & 100.4 & 101.6 & 101.9 \\
\hline 3 & 99.7 & 100.2 & 100.5 & 102.5 & 102.8 \\
\hline 4 & 99.7 & 100.4 & 100.9 & 103.7 & 103.5 \\
\hline 5 & 100.0 & 100.9 & 101.3 & 104.7 & 104.4 \\
\hline 6 & 100.1 & 101.5 & 101.6 & 105.9 & 105.1 \\
\hline 7 & 100.7 & 101.6 & 101.8 & 107.3 & 106.0 \\
\hline 8 & 101.7 & $102.2^{*}$ & 102.1 & 108.6 & 107.1 \\
\hline 9 & 102.6 & 102.3 & 102.3 & 110.4 & 108.7 \\
\hline 10 & 103.5 & 103.0 & 102.9 & 111.9 & 110.9 \\
\hline 11 & $104.4^{*}$ & 103.2 & 103.2 & $113.5^{*}$ & 113.3 \\
\hline 12 & 105.3 & 103.1 & 103.6 & 115.4 & 116.0 \\
\hline 13 & 105.8 & 103.5 & 103.8 & 117.0 & 119.4 \\
\hline 14 & 107.1 & 103.7 & 104.0 & 118.3 & 122.7 \\
\hline \multicolumn{6}{|c|}{$\begin{array}{l}\text { Average annual } \\
\text { rate of change from } \\
\text { trough to: }\end{array}$} \\
\hline Peak & $1.6 \%$ & $1.1 \%$ & $1.7 \%$ & $4.7 \%$ & - \\
\hline $\begin{array}{l}14 \text { quart } \\
\text { trough }\end{array}$ & 2.0 & 1.0 & 1.1 & 4.9 & $6.0 \%$ \\
\hline
\end{tabular}

trough (not shown in table). expansion was characterized by a slow start, but once the momentum started, it carried through 1973; and 1974 continues strong relative to its trough reference point.

\section{CONSUMER PRICES}




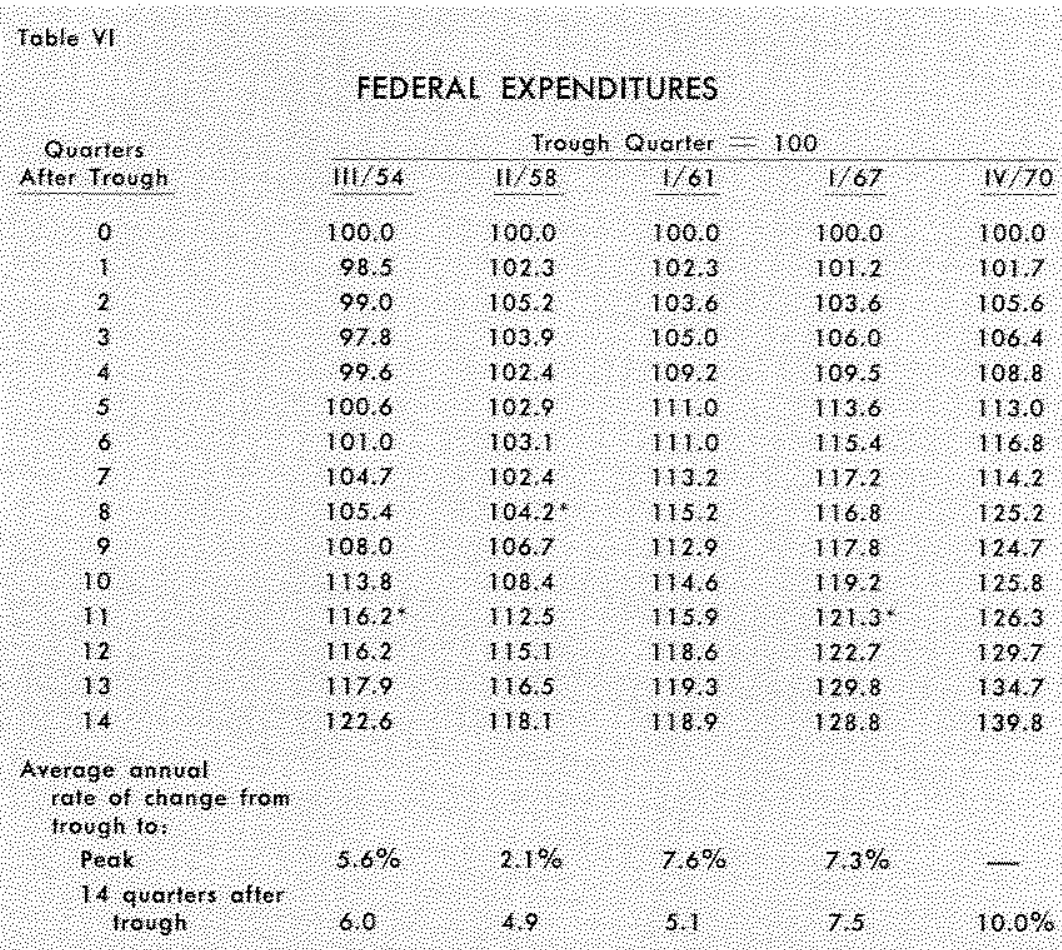

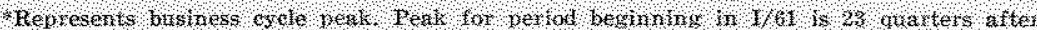
trough hol shown in thile:
In fact, the advance of Government spending in the latest expansion has kept pace with the 1967-69 period - a period when Viet Nam hostlities were still in effect. Even though the composition of expenditures has shifted away from wartime production, the increase of total Federal spending in the current expansion is just as rapid as from 1967 to 1969.

The other chief policy indicator summarized here is the money stock (Table VII). The advance of money since late 1970 has been rapid and has paralleled almost exactly the early stages of the 1967.69 expansion. It is also of in terest to note that the other paths of money expansion (with the possible exception of the 1957-59 expansion) show a downturn just prior to the peak of economic activity; that is, the end of all economic expansions in the past has been preceded by a marked slowing in money growth. No such marked slowing is evident for the path of money in the current expansion, although latest data indicate

Fros - Examination of prices relative to other periods of cyclical expansion indicates that the price experience for the most recent expansion stands out quite dramatically, along with the experience of the previous expansion - 1967-69 (Table V, p. 5). The advance of prices in the current expansion started out almost identical to the $1967-69 \mathrm{ex}-$ pansion. Prices then slowed, but accelerated again more recently. This pattern of price movement, a slow rise followed by a sharp acceleration, was influenced in considerable measure by price and wage controls. Nevertheless, of the five postwar expansions, the last two stand out relative to the others in terms of price performance.

Follog warables -... It is of analytical interest to examine the movement of policy variables in the current expansion. Comparison of Federal expenditures in the current expansion with other postwar expansions indicates that the most recent advance has paralleled that of the 196769 expansion ( Table VI). All other postwar expansions showed less Federal activity, as measured by Federal expenditures, than does the current expansion.

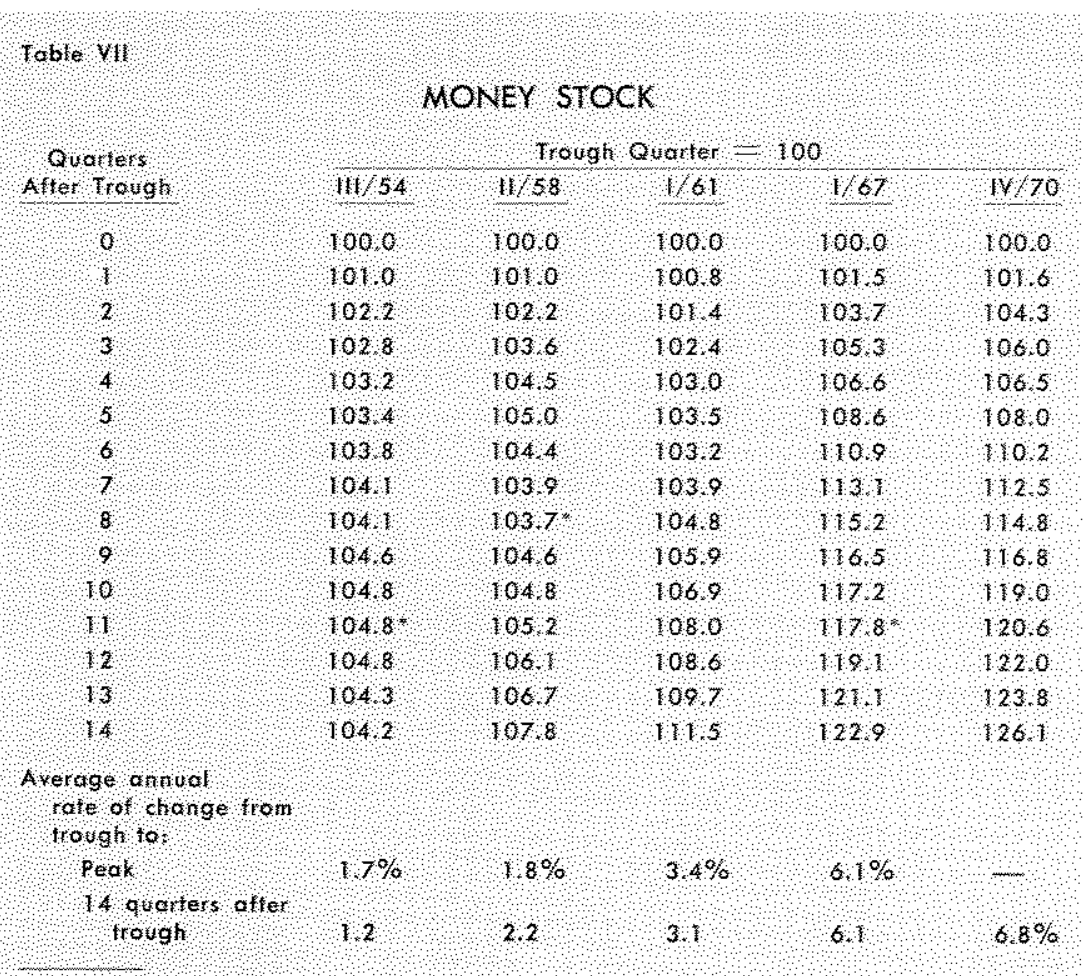

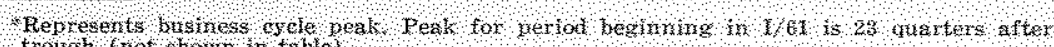
tout frot thown thite)

signs of slight slowing in the rate of monetary expansion beginning in third quarter 1973 (11th quarter after the IV/1970 trough).

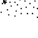


Another aspect of the tables that is of interest is that when viewed together, the latest expansion is different in two respects - in terms of the policy variables and in terms of prices; the two latest expmenions are characterized by extremes. The real variables do not demonstrate the same patterk. During periods of economic expansion, industrial production and payroll employment do not seem to be systematically related to the movements of the policy variables. For the last seven years - covering the two most recent expansions - monetary and fiscal policy have been much more stimulative than in previous expansions, with the chief effect being that prices have increased more rapidly than otherwise with little noticeable effect on production and employment.

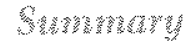

The first half of 1974 for the U.S. economy was a failure from the standpoint of the degree of achievement of goals relating to economic growth and price stability. Yet, upon closer examination of the data, whether or not the economy experienced recession is still an open question. Only the time series of real GNP definitely supports the notion that a recession did occur; other measures of real economic activity though they have slowed - have not demonstrated such weakness when viewed in perspective. It seems that rapid inflation and/or substantial changes in relative prices cause considerable difficulty in the measurement of overall price levels which, in tum, creates problems in the conversion of nominal magnitudes to "real" magnitudes.

Examination of the current expansion from a longerterm perspective indicates that the advance of production and employment is quite similar to previous expansions. Where the current expansion stands out relative to most other expansions is in the movement of the price level and in the policy variables. During the expansion period from late 1970 to the present. substantial monetary and fiscal stimtlus has caused a rapid rise in the price level without commensurate gains in production and employment.

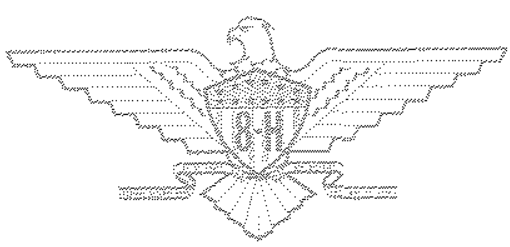

